\title{
Comparison of response surface model with neural network in predicting the tensile strength of friction stir welded RDE-40 aluminium alloy
}

\author{
Balasubramanian V, Lakshminarayanan A K \\ Department of Manufacturing Engineering, Annamalai University, Annamalai Nagar-608002, India \\ e-mail: visvabalu@yahoo.com
}

\begin{abstract}
Friction stir welding (FSW) is an innovative solid state joining technique and has been employed in aerospace, rail, automotive and marine industries for joining aluminium, magnesium, zinc and copper alloys. The FSW process parameters such as tool rotational speed, welding speed, axial force etc., play a major role in deciding the weld quality. This paper focuses two innovative methods such as response surface methodology and artificial neural network are used to predict the tensile strength of friction stir welded RDE-40 aluminium alloy. The experiments were conducted based on three factors, three-level, and central composite face centered design with full replications technique and mathematical model is developed. The results obtained through response surface methodology were compared with artificial neural networks. It was found that the error rate predicted by the artificial network was smaller than predicted by the response surface methodology.
\end{abstract}

Key words: Friction stir welding, aluminium alloy, tensile strength, response surface methodology, artificial neural network

\section{INTRODUCTION}

Generally, the quality of a weld joint is directly influenced by the welding input parameters during the welding process; therefore, welding can be considered as a multi input multi-output process [1]. Unfortunately, a common problem that has faced the manufacturer is the control of the process input parameters to obtain a good welded joint with the required weld quality with minimal detrimental residual stresses and distortion [2]. Traditionally, it has been necessary to determine the weld input parameters for every new welded product to obtain a welded joint with the required specifications. To do so, requires a time-consuming trial and error development effort, with weld input parameters chosen by the skill of the engineer or machine operator [3]. Then welds are examined to determine whether they meet the specification or not. Finally the weld parameters can be chosen to produce a welded joint that closely meets the joint requirements. Also, what is not achieved or often considered is an optimized welding parameters combination, since welds can often be produced with very different parameters. In other words, there is often a more ideal welding parameters combination, which can be used if it can only be determined. In order to overcome this problem, various prediction methods can be applied to define the desired output variables through developing mathematical models to specify the relationship between the input parameters and output variables. In the last two decades, design of experiment (DOE) techniques has been used to carry out such prediction. Evolutionary algorithms and computational network have also grown rapidly and been adapted for many applications in different areas [4]. Recently, in the fields of materials joining, computer aided ANN modeling has gained increased importance [5]. Most researchers have investigated the prediction of process parameters for better weld bead quality of fusion welding processes. Hasan Okuyucu [6] et al., (2005) showed the possibility of the use of neural networks for the calculation of the mechanical properties of friction stir welded (FSW) aluminium plates incorporating process parameters such as rotational speed and welding speed. In this work, two innovative methods such as response surface methodology and artificial neural network are used to predict the tensile strength of friction stir welded RDE-40 aluminium alloy.

\section{EXPERIMENTAL WORK}

\section{A. Identifying the Important Parameters.}

From the literature [9] and the previous work done $[7,8]$ in our laboratory among the many independently controllable primary and secondary process parameters affecting the tensile strength, the primary process parameters viz rotational speed $(\mathrm{N})$ and welding speed $(\mathrm{S})$, and axial Force $(\mathrm{F})$, were selected as process parameters for this study. The rotational speed $(\mathrm{N})$ and welding speed (S), and axial force (F) are the primary parameters contributing to the heat input and subsequently influencing the tensile strength variations in the friction stir welded aluminium alloy joints.

\section{$B$. Finding the Working Limits of Parameters}

A large number of trial runs were carried out using 6 $\mathrm{mm}$ thick rolled plates of RDE-40 aluminium alloy to find out the feasible working limits of FSW process parameters. The chemical composition and mechanical properties of RDE-40 aluminium alloy are presented in Table 1. Different combinations of process parameters 
were used to carryout the trial runs. This was carried out by varying one of the factors while keeping the rest of them at constant values. The working range of each process parameter was decided upon by inspecting the macrostructure (cross section of weld) for a smooth appearance without any visible defects such as tunnel defect, pinhole, kissing bond, lazy S, etc. and presented in Table.2

\section{C.Conducting the Experiments}

The rolled plates of $6 \mathrm{~mm}$ were cut into the required sizes $(300 \mathrm{~mm} \times 150 \mathrm{~mm}$ ) by power hacksaw cutting and milling. The design matrix chosen to conduct the experiments was a central composite face centered design, which is shown in Table 3 . Square butt joint configuration was prepared to fabricate FSW joints. A nonconsumable, rotating tool made of high carbon steel was used to fabricate FSW joints. An indigenously designed and developed machine (15 hp; 3000 rpm; $25 \mathrm{kN}$ ) was used to fabricate the joints. The welded joints were sliced using a power hacksaw and then machined to the required dimensions. American Society for Testing of Materials (ASTM E8M-04) guidelines was followed for preparing the test specimens. Three tensile specimens were prepared from each joint to evaluate the transverse tensile strength. Tensile test was carried out in $100 \mathrm{kN}$, electro-mechanical controlled Universal Testing Machine (Make: FIE-Bluestar, India; Model: UNITEK-94100) and the average of the three results is presented in Table 3 .

\section{PREDICTION OF TENSILE STRENGTH}

\section{A. Mathematical Model by Response Surface Methodology (RSM)}

In practical applications of RSM, it is necessary to develop a fitting model for the response surface, and it is typically driven by some unknown physical mechanism. For prediction, the response surface method (RSM) is practical, economical and relatively easy for use [10]. In this present investigation, to correlate the process parameters and the tensile strength of friction stir welded RDE-40 joints; a second order quadratic model is developed to predict the tensile strength of friction stir welded RDE-40 joints based on experimentally measured tensile strength. Representing the tensile strength of the welded joints "TS", the response function can be expressed as TS $=f(N, S, F)$. The model chosen includes the effects of main and interaction effect of all factors. The second order polynomial (regression) equation used to represent the response surface ' $Y$ ' is given by

$Y=b_{0}+\sum b_{i} x_{i}+\sum b_{i i} x_{i}^{2}+\sum b_{i j} x_{i} x_{j}+e_{r}$ and for three factors, the selected polynomial could be expressed as
$T S=b_{0}+b_{1}(N)+b_{2}(S)+b_{3}(F)+b_{11}\left(N^{2}\right)+b_{22}\left(S^{2}\right)+b_{33}\left(F^{2}\right)+b_{12}(N S)+$ $\mathrm{b}_{13}(\mathrm{NF})+\mathrm{b}_{23}(\mathrm{SF})$

In order to estimate the regression coefficients, a number of experimental design techniques are available. In this work, central composite face centered design (Table 3) was used which fits the second order response surfaces very accurately. Central composite face centered (CCF) design matrix with the star points are at the center of each face of factorial space was used, so $(y= \pm 1$. This variety requires 3 levels of each factor. CCF designs provide relatively high quality predictions over the entire design space and do not require using points outside the original factor range. The upper limit of a factor was coded as +1 , and the lower limit was coded as 1 . All the coefficients were obtained applying central composite face centered design using the Design Expert statistical software package. After determining the significant coefficients (at 95\% confidence level), the final model was developed using only these coefficients and the final mathematical model to estimate tensile strength is given below:

$\begin{array}{lr}\text { Tensile strength (TS) }=\{311.44+16.50(\mathrm{~N})-5.30(\mathrm{~S})+ \\ 5.00(\mathrm{~F})-4.50(\mathrm{NS})- & 8.75(\mathrm{NF})+ \\ \left.4.50(\mathrm{SF})-35.59 \mathrm{~N}^{2}-58.59 \mathrm{~S}^{2}-12.09 \mathrm{~F}^{2}\right\} & \end{array}$

\section{B.1. Checking the Adequacy of Model}

The adequacy of the developed model was tested using the analysis of variance (ANOVA) technique and the results of second order response surface model fitting in the form of analysis of variance (ANOVA) are given in Table 4. The determination coefficient $\left(R^{2}\right)$ indicates the goodness of fit for the model. In this case, the value of the determination coefficient $\left(R^{2}=0.96998\right)$ indicates that only $3 \%$ of the total variations are not explained by the model. The value of adjusted determination coefficient (adjusted $R^{2}=0.9539$ ) is also high, which indicates a high significance of the model. Predicted $R^{2}$ is also made a good agreement with the adjusted $R^{2}$. The value of probability $>\mathrm{F}$ in Table 4 for model is less than 0.05 , which indicates that the model is significant. In the same way, rotational speed $(\mathrm{N})$, welding speed $(\mathrm{S})$ and axial force $(\mathrm{F})$, interaction effect of rotational speed with welding speed, interaction effect of rotational speed with axial force (NF), interaction effect of welding speed with axial force (SF) and second order term of rotational speed $(\mathrm{N})$, welding speed (S) and axial force (F) have significant effect. Lack of fit is non significant as it is desired [11]. All the above consideration indicates an excellent adequacy of the regression model.

\section{Artificial Neural Network (ANN)}

ANNs are computational models, which replicate the 
function of a biological network, composed of neurons and are used to solve complex functions in various applications. Neural networks consist of simple synchronous processing elements that are inspired by the biological nerve systems. The basic unit in the ANN is the neuron. Neurons are connected to each other by links known as synapses; associated with each synapse there is a weight factor. Details on the neural network modeling approach are given in else where [13].One of the most popular learning-algorithms is the back-propagation (BP) algorithm. In this present study, BP algorithm is used with a single hidden layer improved with numerical optimization techniques called Levenberg- Marquardt (LM) [14].The architecture of ANN used in this study is $3-12,-1,3$ corresponding to the input values, 12 to the number of hidden layer neurons and 1 to the output. The topology architecture of feed-forward three-layered back propagation neural network is illustrated in Fig.1. MATLAB 7.1 has been used for training the network model for tensile strength prediction. The training parameters used in this investigation are shown in Table.5 The neural network described in this paper, after successful training, will be used to predict the tensile strength of friction stir welded joints of RDE-40 aluminium alloy within the trained range. Statistical methods were used to compare the results produced by the network. Errors occurring at the learning and testing stages are called the root-mean squared (RMS), absolute fraction of variance $\left(R^{2}\right)$, and mean error percentage values. These are defined as follows, respectively:

$$
\begin{aligned}
& \text { RMS }=\left((1 / p) \sum|t j-o j|^{2}\right)^{1 / 2}, \\
& R^{2}=1-\left(\frac{\sum_{j}(t j-o j)^{2}}{\sum_{j}(o j)^{2}}\right), \\
& \text { mean error }=\frac{1}{p} \sum_{j}\left(\frac{t j-o j}{t j} 100\right) .
\end{aligned}
$$

Where, $p$ no of patterns, $t_{j}$ Target tensile strength, $o_{j}$ Actual tensile strength

\section{COMPARISON OF ANN AND RS MODELS}

The trend in the modelling using RSM has a low order non-linear behaviour with a regular experimental domain and relatively small factors region, due to its limitation in building a model to fit the data over an irregular experimental region. Moreover, the main advantage of RSM is its ability to exhibit the factor contributions from the coefficients in the regression model. This ability is powerful in identifying the insignificant main factors and interactions factors or insignificant quadratic terms in the model and thereby can reduce the complexity of the problem. On the other hand, this technique required good definition of ranges for each factor to ensure that the response(s) under consideration is changing in a regular manner within this range. It noted that ANNs perform better than the other techniques, especially RSM when highly non-linear behaviour is the case. Also, this technique can build an efficient model using a small number of experiments; however the technique accuracy would be better when a larger number of experiments are used to develop a model. On the other hand, the ANN model itself provides little information about the design factors and their contribution to the response if further analysis has not been done. Generation of ANN model requires a large number of iterative calculations whereas it is only a single step calculation for a response surface model. Depending of the nonlinearity of the problem and the number of parameters, an ANN model may require a high computational cost to create. Although computationally much more costly than a response model, ANN model led to comparatively accurate tensile strength predictions as shown in Table.6. The mean errors for ANN and RS model are about $0.258847 \%$ and $0.769831 \%$ respectively. The error against observation order of both the models is compared in Fig.2.

\section{CONCLUSIONS}

This paper has described the use of Design of Experiments (DOE) for conducting experiments. Two innovative models, response surface and artificial neural network (ANN), for predicting tensile strength of friction stir welded RDE-40 aluminium alloy. From this investigation, following important conclusions are derived.

(1) Amathematical model has been developed to predict the tensile strength of friction stir welded RDE-40 aluminium alloy joints at 95\% confidence level, incorporating FSW process parameters.

(2) The predictive ANN model is found to be capable of better predictions of tensile strength within the range that they had been trained. The results of the ANN model indicate it to be much more robust and accurate in estimating the values of tensile strength when compared with the response surface model.

\section{ACKNOWLEDGEMENTS}

The authors are grateful to the Department of Manufacturing Engineering, Annamalai University, Annamalainagar, Tamil Nadu, India for extending the facilities of Metal Joining Laboratory and Materials Testing Laboratory to carryout this investigation. The authors also wish to express their sincere thanks to Naval Research Board (NRB), Ministry of Defence, New Delhi for the 
financial support to carryout this investigation through sponsored project No.DNRD/05/4003/NRB/67. The authors also acknowledge the help rendered by $\mathrm{Mr}$. Subbiah, Manager, LTM, Chennai, India to procure the base material.

\section{REFERENCES}

[1] I.S. Kim, K.J. Son, Y.S. Yang, P.K.D.V. Yaragad, Sensitivity analysis for process parameters in GMA welding processes using a factorial design method International Journal of Machine Tools \& Manufacture 43 (2003) 763769

[2] N. Murugan, V. Gunaraj, Prediction and control of weld bead geometry and shape relationships in submerged arc welding of pipes, Journal of Materials Processing Technology 168 (2005) 478487

[3] Hsien-Yu Tseng, Welding parameters optimization for economic design using neural approximation and genetic algorithm, International Journal of Advanced Manufacturing technology, 27 (2006) 897901

[4] D. Kim, S. Rhees, H. Park, Modelling and optimization of GMA welding process by genetic algorithm and response surface methodology, International journal of production research. 40 (2002) 16111699.

[5] Tuncay Erzurumlu, Hasan Oktem, Comparison of response surface model with neural network in determining the surface quality of moulded parts, Materials and Design 28 (2007) 459465

[6] Hasan Okuyucu, Adem Kurt, Erol Arcaklioglu, Artificial neural network application to the friction stir welding of aluminum plates, Materials and Design (2005)
[7] Won Bae Lee, Mechanical properties related to microstructural variation of $6061 \mathrm{Al}$ alloy joints by friction stir welding, Material Transactions. Vol. 45(5), (2004), 1700-1705

[8] K. Elangovan and V. Balasubramanian, Influences of pin profile and rotational speed of the tool on the formation of friction stir processing zone in AA2219 aluminium alloy, Journal of Materials Science Engineering -A459 (2007) 7-18.

[9] K. Elangovan and V. Balasubramanian, Effect of tool pin profile and axial force on the formation of friction stir processing zone in AA6061 aluminium alloy, International Journal of Advanced Manufacturing Technology, (In Press).

[10] Bor-Tsuen Lin, Ming-Der Jean, Jyh-Horng Chou, Using response surface methodology for optimizing deposited partially stabilized zirconia in plasma spraying, Applied Surface Science 253 (2007) 32543262

[11] S. Kumar, P.Kumar, H.S.Shan, 'Effect of evaporative casting process parameters on the surface roughness of $\mathrm{Al}-7 \% \mathrm{Si}$ alloy castings, Material Processing Technology, 182 (2007), 615-623.

[12] Z.Zhang, K.Friedrich, Artificial neural networks applied to polymer composites: a review, Composites science and technology ,63, 2003, 2029-2044.

[13] Erol Arcakhoglu, Abdullah cavusoglu, Ali Erisen, Thermodynamic analyses of refrigerant mixtures using artificial neural networks, Applied Energy 78 (2004) 219-230.

Table 1(a) Chemical composition (wt \%) of base metal

\begin{tabular}{lllllllll}
\hline $\mathrm{Zn}$ & $\mathrm{Mg}$ & $\mathrm{Mn}$ & $\mathrm{Fe}$ & $\mathrm{Si}$ & $\mathrm{Cu}$ & $\mathrm{Cr}$ & $\mathrm{Ti}$ & $\mathrm{Al}$ \\
\hline 3.62 & 2.49 & 0.18 & 0.28 & - & 0.1 & - & - & Bal \\
\hline
\end{tabular}

Table 1(b) Mechanical properties of base metal

\begin{tabular}{ccccc}
\hline $\begin{array}{c}\text { Yield } \\
\text { Strength } \\
\text { (MPa) }\end{array}$ & $\begin{array}{c}\text { Ultimate } \\
\text { Tensile } \\
\text { Strength } \\
\text { (MPa) }\end{array}$ & $\begin{array}{c}\text { Elongation } \\
\text { (\%) }\end{array}$ & $\begin{array}{c}\text { Reduction } \\
\text { in cross } \\
\text { sectional } \\
\text { area (\%) }\end{array}$ & $\begin{array}{c}\text { Hardness } \\
\text { (VHN) }\end{array}$ \\
\hline 304 & 383 & 15.0 & 10.25 & 130 \\
\hline
\end{tabular}


Balasubramanian.V et al : omparison of response surface model with neural network in predicting.,

Table 2 Important factors and their levels for RDE-40 aluminum alloy

\begin{tabular}{llccccc}
\hline \multirow{2}{*}{ Parameter } & Notation & Unit & \multicolumn{3}{c}{ Levels } \\
\cline { 5 - 7 } & & & & $(-1)$ & $(0)$ & $(+1)$ \\
\hline 1 & Rotational Speed & $\mathrm{N}$ & $\mathrm{rpm}$ & 1200 & 1400 & 1600 \\
2 & Welding Speed & $\mathrm{S}$ & $\mathrm{mm} / \mathrm{min}$ & 22 & 45 & 75 \\
3. & Axial Force & $\mathrm{F}$ & $\mathrm{kN}$ & 4 & 6 & 8 \\
\hline
\end{tabular}

Table 3 Experimental design matrix and results

\begin{tabular}{|c|c|c|c|c|c|c|c|c|}
\hline \multirow{2}{*}{ Std } & \multirow{2}{*}{ Run } & \multicolumn{3}{|c|}{ Coded values } & \multicolumn{3}{|c|}{ Real values } & \multirow{2}{*}{$\begin{array}{c}\text { Tensile strength } \\
\text { of the joint } \\
\text { (MPa) }\end{array}$} \\
\hline & & $\mathrm{N}$ & $S$ & $F$ & $\begin{array}{l}\text { Rotational } \\
\text { speed } \\
\text { (rpm) }\end{array}$ & $\begin{array}{l}\text { Welding speed } \\
(\mathrm{mm} / \mathrm{min})\end{array}$ & $\begin{array}{l}\text { Axial } \\
\text { force } \\
(\mathrm{kN})\end{array}$ & \\
\hline 1 & 15 & -1 & -1 & -1 & 1200 & 22 & 4 & 180 \\
\hline 2 & 9 & +1 & -1 & -1 & 1600 & 22 & 4 & 238 \\
\hline 3 & 8 & -1 & +1 & -1 & 1200 & 75 & 4 & 170 \\
\hline 4 & 7 & +1 & +1 & -1 & 1600 & 75 & 4 & 211 \\
\hline 5 & 10 & -1 & -1 & +1 & 1200 & 22 & 8 & 200 \\
\hline 6 & 18 & +1 & -1 & +1 & 1600 & 22 & 8 & 224 \\
\hline 7 & 5 & -1 & +1 & +1 & 1200 & 75 & 8 & 209 \\
\hline 8 & 17 & +1 & +1 & +1 & 1600 & 75 & 8 & 214 \\
\hline 9 & 1 & -1 & 0 & 0 & 1200 & 45 & 6 & 255 \\
\hline 10 & 16 & +1 & 0 & 0 & 1600 & 45 & 6 & 292 \\
\hline 11 & 11 & 0 & -1 & 0 & 1400 & 22 & 6 & 258 \\
\hline 12 & 12 & 0 & +1 & 0 & 1400 & 75 & 6 & 243 \\
\hline 13 & 3 & 0 & 0 & -1 & 1400 & 45 & 4 & 296 \\
\hline 14 & 20 & 0 & 0 & +1 & 1400 & 45 & 8 & 298 \\
\hline 15 & 2 & 0 & 0 & 0 & 1400 & 45 & 6 & 317 \\
\hline 16 & 13 & 0 & 0 & 0 & 1400 & 45 & 6 & 315 \\
\hline 17 & 4 & 0 & 0 & 0 & 1400 & 45 & 6 & 309 \\
\hline 18 & 14 & 0 & 0 & 0 & 1400 & 45 & 6 & 311 \\
\hline 19 & 6 & 0 & 0 & 0 & 1400 & 45 & 6 & 312 \\
\hline 20 & 19 & 0 & 0 & 0 & 1400 & 45 & 6 & 314 \\
\hline
\end{tabular}

Table 4 ANOVA results for tensile strength (Only significant terms).

\begin{tabular}{lccccc}
\hline Source & Sum of squares & df & Mean square & F Value & $\begin{array}{c}\text { p-value } \\
\text { Prob }>\text { F }\end{array}$ \\
\hline Model & 44763.17 & 9 & 5307.02 & 342.33 & $<0.0001$ \\
N-Rotational speed & 2722.50 & 1 & 2722.50 & 175.61 & $<0.0001$ \\
S-Welding speed & 280.90 & 1 & 280.90 & 18.12 & 0.0017
\end{tabular}




\begin{tabular}{lccccc} 
Axial force & 250.00 & 1 & 250.00 & 16.13 & 0.0025 \\
AB & 162.00 & 1 & 162.00 & 10.45 & 0.0090 \\
AC & 612.50 & 1 & 612.50 & 39.51 & $<0.0001$ \\
BC & 162.00 & 1 & 162.00 & 10.45 & 0.0090 \\
A $^{2}$ & 3483.46 & 1 & 3483.46 & 224.70 & $<0.0001$ \\
B $^{2}$ & 9440.46 & 1 & 9440.46 & 608.95 & $<0.0001$ \\
C $^{2}$ & 402.02 & 1 & 402.02 & 25.93 & 0.0005 \\
Residual & 155.03 & 10 & 15.50 & & \\
Lack of Fit & 113.03 & 5 & 22.61 & 2.69 & 0.1506 \\
Cor.Total & 47918.20 & 19 & & & \\
\hline
\end{tabular}

Table 5 Training parameters used

\begin{tabular}{lc}
\hline Number of Input nodes & 3 \\
Number of hidden nodes (feed forward) & 11 \\
Number of output nodes & 1 \\
Learning rule & Levenburg marquatt \\
No of epochs & 500 \\
Mu & 0.01 \\
\hline
\end{tabular}

Table 6 Comparison between RSM and ANN

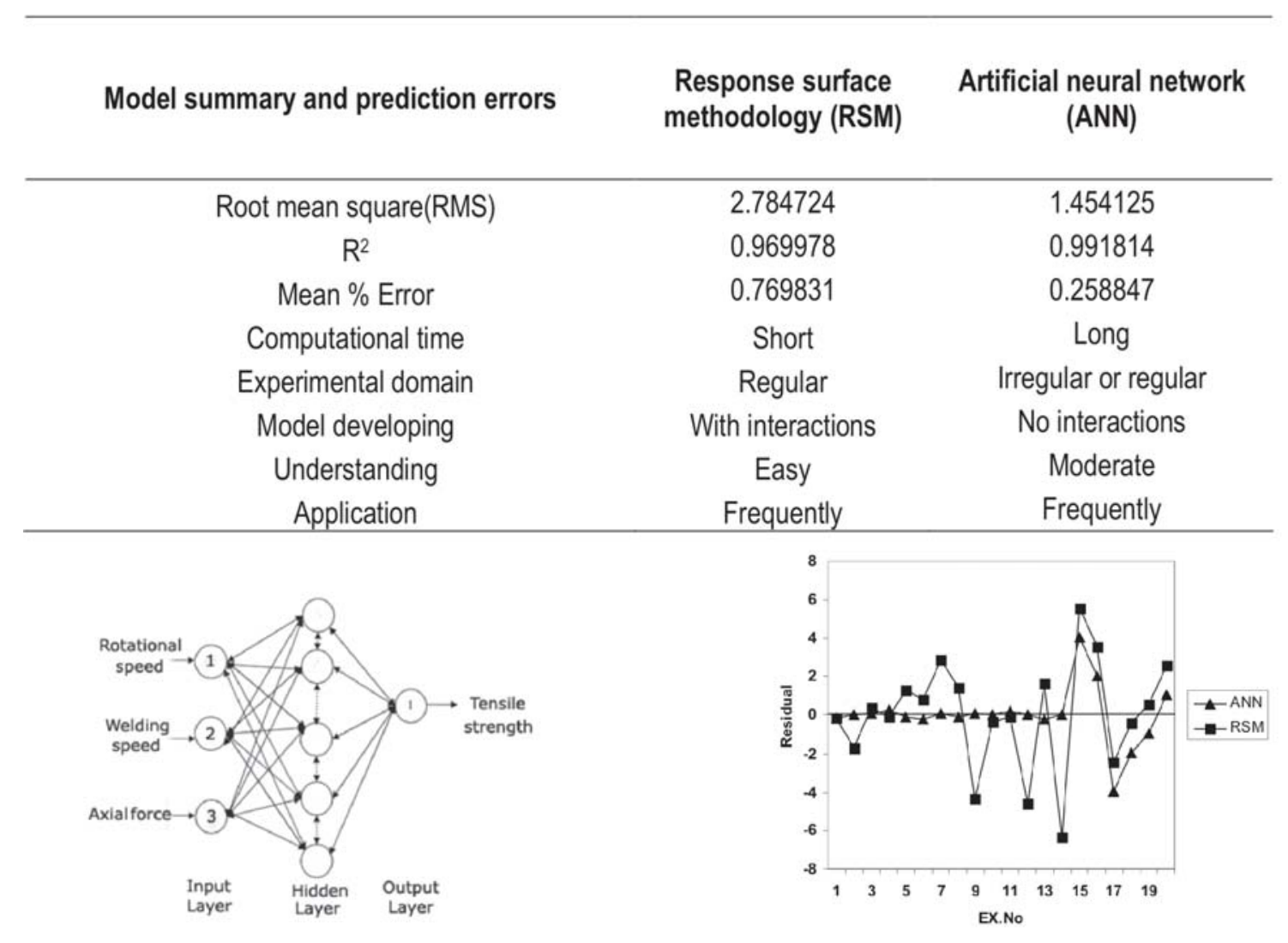

